\title{
Hemoptysis and Endometriosis: An Unusual Association - Case Report and Review of the Literature
}

\section{Hemoptise e endometriose: uma associação não usual - relato de caso e revisão da literatura}

\author{
Joao Paulo Leonardo-Pinto ${ }^{1}$ Cristina Laguna Benetti-Pinto ${ }^{1}$ Iuri Quagliato ${ }^{1}$ Daniela Angerame Yela ${ }^{1}$ \\ ${ }^{1}$ Universidade Estadual de Campinas, Campinas, SP, Brazil \\ Address for correspondence Daniela Angerame Yela, Alexander \\ Rev Bras Ginecol Obstet 2018;40:300-303. \\ (e-mail: yela@unicamp.br).
}

\begin{abstract}
Keywords

- endometriosis

- hemoptysis

- thoracic endometriosis syndrome

\section{Resumo}

Palavras-chave

- endometriose

- hemoptise

- síndrome da endometriose torácica

Thoracic endometriosis syndrome is a rare condition that includes four entities: catamenial pneumothorax, catamenial hemothorax, catamenial hemoptysis and lung nodules. We describe the case of a 23-year-old woman with complaints of hemoptysis during menstrual period in the two years prior to the appointment. Initially, a treatment for tuberculosis was established with no success. Further investigation showed a $4 \mathrm{~mm}$ nodule in the right lung, and the transvaginal ultrasonography indicated the presence of deep endometriosis. Considering the occurrence of symptoms only during menses, an empirical therapy was instituted with remission of the complaints.

A síndrome da endometriose torácica é uma condição rara que inclui quatro entidades: pneumotórax catamenial, hemotórax catamenial, hemoptise catamenial e nódulos pulmonares. Descrevemos o caso de uma mulher de 23 anos de idade com queixas de hemoptise durante o período menstrual por 2 anos. Inicialmente, um tratamento para a tuberculose foi estabelecido sem sucesso. Uma investigação adicional mostrou um nódulo de $4 \mathrm{~mm}$ no pulmão direito, e a ultrassonografia transvaginal indicou a presença de endometriose profunda. Considerando a ocorrência de sintomas somente durante a menstruação, uma terapia empírica foi instituída com remissão das queixas.
\end{abstract}

\section{Introduction}

Thoracic endometriosis syndrome (TES) is one of the extrapelvic forms of endometriosis, and it can involve the airways, pleura and lung parenchyma. This rare condition includes four entities: catamenial pneumothorax, catamenial hemothorax, catamenial hemoptysis and lung nodules. ${ }^{1,2}$

Considered an extremely exceptional condition, the TES diagnosis is repeatedly delayed and, many times, confounded with other diseases, mainly when it is presented as hemoptysis, which is even rarer. The literature evidence about TES is very sparse and most of the findings come from case reports, which suggests an important limitation regarding the data. ${ }^{2,3}$

Cyclic manifestations of pulmonary diseases, such as chest or shoulder pain, dyspnea and hemoptysis, which occur along with the menstrual period, should be considered as an alert for any gynecologist or clinician. In such cases, the hypothesis of TES should be seriously considered, and a further investigation with imaging techniques ought to be implemented for diagnosis, despite of nonspecific findings. ${ }^{4}$

Clinical management, due to its conservative character, should be considered as the first-line therapy, and the received

October 27, 2017

accepted

January 24, 2018

published online

April 27, 2018
DOI https://doi.org/

10.1055/s-0038-1646780.

ISSN $0100-7203$.
Copyright $\odot 2018$ by Thieme Revinter

Publicações Ltda, Rio de Janeiro, Brazil
License terms

c) $(1) \$$ 


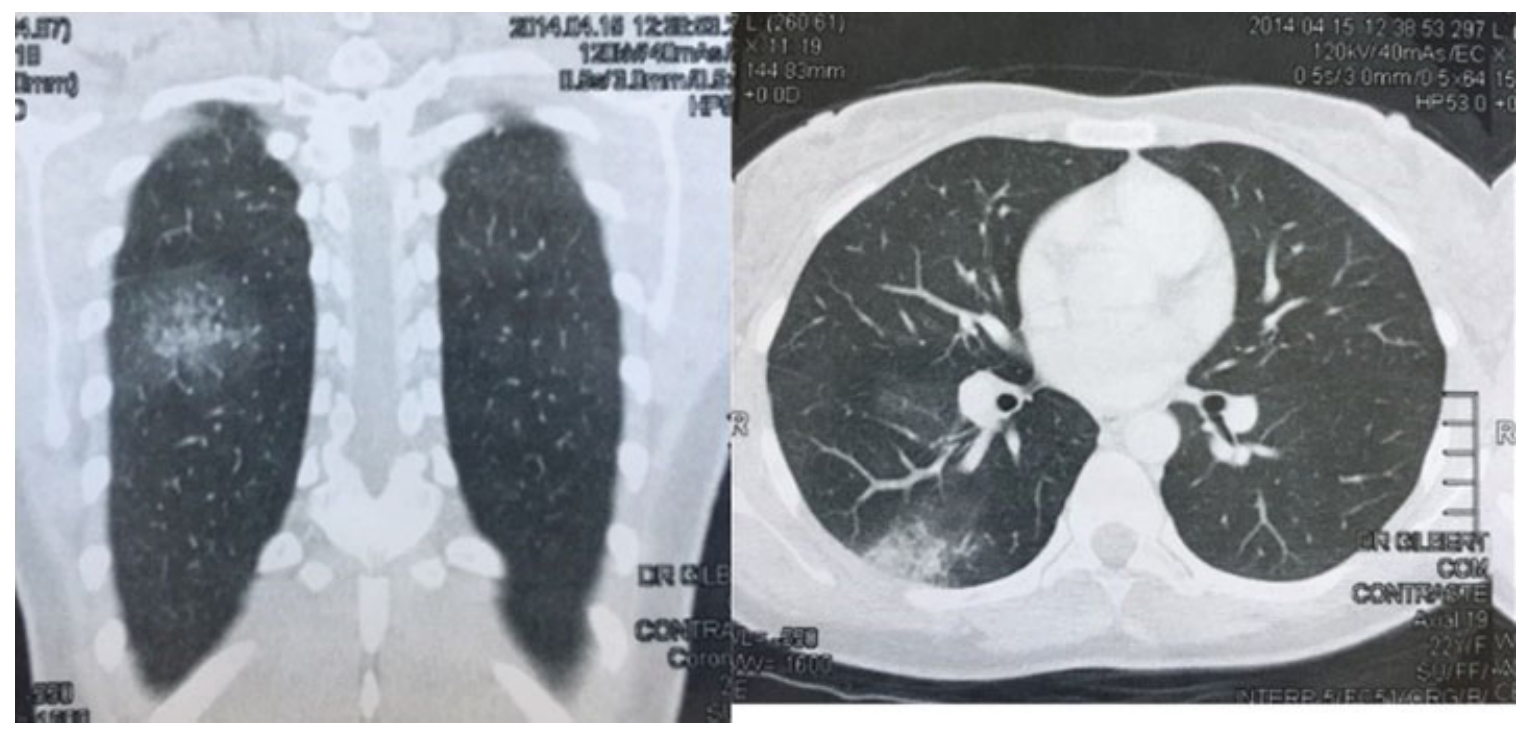

Fig. 1 An area of ground glass haze in the upper lobe of the right lung.

surgical approach must be cogitated when the pharmacological approach fails. ${ }^{5,6}$

\section{Case report}

A 23-year-old woman presented with complaints of hemoptysis during the menstrual period, associated with pain in the right shoulder for the past 2 years, with no prior background of smoking or tuberculosis. At admission, her clinical examination and chest X-ray showed no abnormality. She was clinically treated for tuberculosis for several times; however, there was no remission of the symptoms.

Taking into consideration that the hemoptysis occurred only during menses, an inquiry about endometriosis was performed, and the patient revealed that dyspareunia and dysmenorrhea were recurrent.

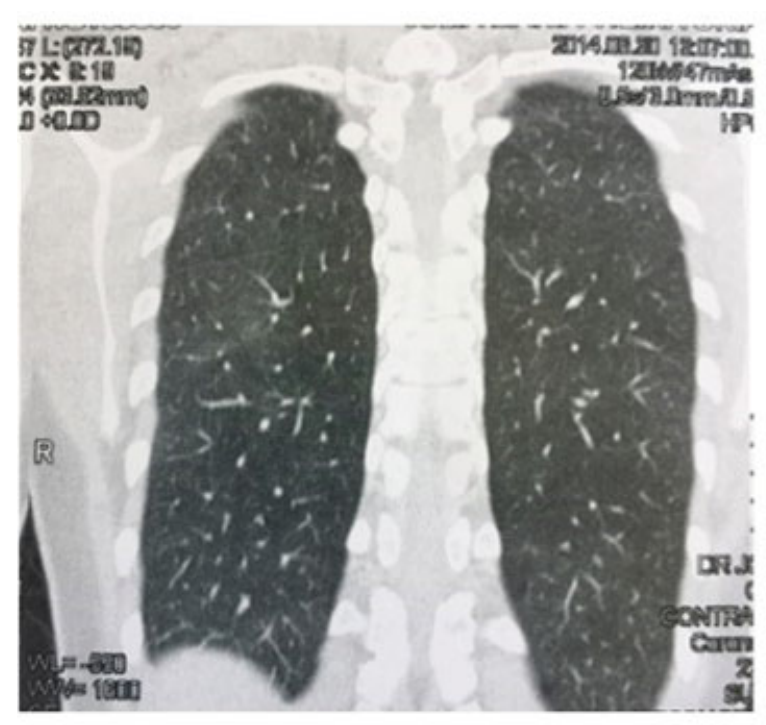

Further investigation with computed tomography (CT) scans during menses showed an area of ground glass haze in the upper

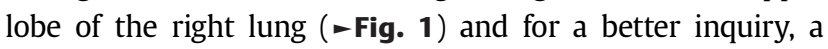
bronchoscopy was performed between menses, and the bronchial washing turned to be negative. As a complementary investigation, the patient underwent transvaginal ultrasonography to investigate the presence of pelvic endometriosis, which was a positive finding. Endometriosis was apparently affecting the posterior fornix and the sacral-uterine ligament. Considering the emergence of symptoms during menses, an empirical treatment with Dienogest ( $2 \mathrm{mg} /$ day) was established.

The first follow-up took place two months after the beginning of therapy, and the patient was clinically asymptomatic. A control CT scan was performed and revealed a current recovery of the affected area (-Fig. 2). After the oneyear follow-up, the patient remains clinically asymptomatic.

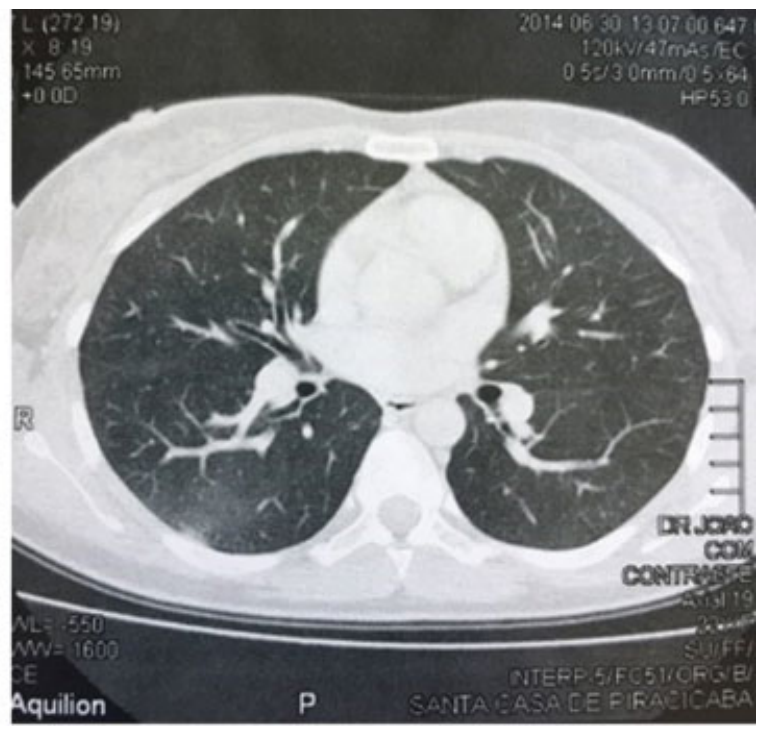

Fig. 2 Recovery on the affected area (computed tomography image without an area of ground glass haze in the upper lobe of the right lung). 


\section{Discussion}

Endometriosis is an estrogen-dependent inflammatory disease that is pronounced by the presence of endometrial tissue outside the uterus, affecting several structures and organs, such as the rectosigmoid colon, rectovaginal septum, uterosacral ligament, bladder and even extrapelvic organs. $^{7}$

Thoracic endometriosis syndrome (TES) is one of the extrapelvic forms of endometriosis, and it can involve the airways, pleura and lung parenchyma. This rare condition includes four entities: catamenial pneumothorax, catamenial hemothorax, catamenial hemoptysis and lung nodules. ${ }^{1,2}$

The most usual appearance of TES is catamenial pneumothorax (73\%), and the rarest is catamenial hemoptysis, jointly with lung nodules (6\% each), as we see in our patient who presents both nodule and hemoptysis. ${ }^{5,8}$

Many theories attempt to clarify the presence of extrapelvic endometrial implants, including intrathoracic implants. Among these theories is coelomic metaplasia, which is based on the hypothesis that both endometrium and pleura have the same embryologic origin, and pathogenic incitements could induce precursor cells to differentiate into endometrial cells. $^{7}$

Another widespread theory, lymphatic or hematogenic dissemination, would also elucidate the occurrence of extrapelvic endometriosis, including TES, and its propensity to the right lung since the right lymphatic drainage system is more complex than the left hemithorax. ${ }^{2,7}$

Clinical manifestation of TES is exceedingly uncommon, and most of the data on this syndrome come from case reports and a retrospective study including 110 patients. Joseph J. et al showed that the mean age at the onset of symptoms was 35 years old and the peak incidence for TES occurred $\sim 5$ years after the incidence of pelvic endometriosis in these patients. ${ }^{8}$

Contrary to what the literature shows, our patient presented both symptoms, pelvic pain and hemoptysis, at the same time, and the main symptom presented by our patient, cyclical hemoptysis, an extremely rare condition, has been described in $\sim 30$ cases in the literature. $^{9}$

Thoracic endometriosis syndrome is considered a thought-provoking diagnostic due to its undefined symptoms, and there is an enormous delay until the disclosure of the diagnosis. Cyclical and recurrent complaints, such as shoulder and chest pain, hemoptysis and dyspnea, mainly when related with pelvic endometriosis background, ought to ring a bell about TES. ${ }^{5,10}$

Not only clinical but also imaging aspects are openended, even though $\mathrm{CT}$ endures as the first-line imaging exam, enabling exclusion of many other lung diseases with similar symptoms and also assisting with the diagnosis in patients with significant clinical description. Magnetic resonance imaging is considered superior to $\mathrm{CT}$, as it can notice blood and its products when performed during menses. ${ }^{5,10}$

Bronchoscopy has a limited role in diagnosis, since most pathologic features are situated in the areas around the lung; as we see in our case reported, the bronchoscopy was completely normal. Regarding video-assisted thoracoscopy, a direct imagining of lung parenchyma, pleura and diaphragmatic shell offers a precise diagnostic. ${ }^{2}$

Considering that there is no definitive treatment for endometriosis, in general, one has to cogitate options for a long-term management. Frequently, hormonal overthrow is the first option in the attempt to control symptoms caused by endometriosis and to postpone or even avoid surgical treatment due to great morbidity. ${ }^{11-13}$

Surgical management by thoracoscopy, or even thoracotomy, aims to remove all the endometriotic tissue and sometimes, a pulmonary segmentectomy is required. This treatment is regarded when clinical approach fails. ${ }^{6-14}$

A variety of drugs has been used to treat endometriosis, including TES, such as combined oral contraceptives, progestogens and gonadotropin-releasing hormone ( $\mathrm{GnRH})$ agonists, and all of them have presented comparable usefulness. Safety, acceptability and cost need to be considered in order to implement a long-term treatment. ${ }^{11}$

Dienogest, a fourth-generation progestogen, has been reported as an effective drug in the treatment of complaints caused by endometriosis, acting through inhibition of GnRH, inducing estrogen deprivation and causing decidualization and atrophy of endometriotic lesions with few and very tolerable side effects. ${ }^{12,15}$

As we see in the case reported, after the treatment with dienogest ( $2 \mathrm{mg} /$ day), our patient remained completely asymptomatic and had no further episodes of hemoptysis or pelvic pain.

In conclusion, TES is a rare disorder that is commonly missed or whose diagnosis is delayed. It may be suspected in women with symptoms during the menstrual period. Computed tomography scan has an important role in presumptive diagnosis. Surgical treatment is an option in some cases; however, the clinical treatment is very effective and suppresses endometriotic tissue growth.

\section{Conflicts of Interest}

The authors declare that they have no conflicts of interest.

\section{References}

1 Pankratjevaite L, Samiatina-Morkuniene D. A case report of thoracic endometriosis - A rare cause of haemothorax. Int J Surg Case Rep 2017;33:139-142 10.1016/j.ijscr.2017.02.052

2 Azizad-Pinto P, Clarke D. Thoracic endometriosis syndrome: case report and review of the literature. Perm J 2014;18(03):61-65 10.7812/TPP/13-154

3 Jitruckthai P. A woman with recurrent hemoptysis, a rare etiology. J Med Assoc Thai 2015;98(06):616-620

4 Nair SS, Nayar J. Thoracic endometriosis syndrome: a veritable Pandora's Box. J Clin Diagn Res 2016;10(04):QR04-QR08 10.7860/ JCDR/2016/17668.7700

5 Alwadhi S, Kohli S, Chaudhary B, Gehlot K. Thoracic endometriosis-A rare cause of haemoptysis. J Clin Diagn Res 2016;10(04): TD01-TD02 10.7860/JCDR/2016/16365.7530

6 Singh K, Agarwal S, Bishay E, Trotter S, Mansur AH. Catamenial hemoptysis. Am J Respir Crit Care Med 2013;187(06):658 10.1164/rccm.201209-1579IM 
7 Koninckx PR, Ussia A, Adamyan L, Wattiez A, Donnez J. Deep endometriosis: definition, diagnosis, and treatment. Fertil Steril 2012;98(03):564-571 10.1016/j.fertnstert.2012.07.1061

8 Joseph J, Sahn SA. Thoracic endometriosis syndrome: new observations from an analysis of 110 cases. Am J Med 1996;100(02): 164-170 10.1016/S0002-9343(97)89454-5

9 Terada Y, Chen F, Shoji T, Itoh H, Wada H, Hitomi S. A case of endobronchial endometriosis treated by subsegmentectomy. Chest 1999;115(05):1475-1478 10.1378/chest.115.5.1475

10 Rousset P, Rousset-Jablonski C, Alifano M, Mansuet-Lupo A, Buy JN, Revel MP. Thoracic endometriosis syndrome: CT and MRI features. Clin Radiol 2014;69(03):323-330 10.1016/j.crad.2013.10.014

11 Guo SW. Recurrence of endometriosis and its control. Hum Reprod Update 2009;15(04):441-461 10.1093/humupd/dmp007
12 Leonardo-Pinto JP, Benetti-Pinto CL, Cursino K, Yela DA. Dienogest and deep infiltrating endometriosis: The remission of symptoms is not related to endometriosis nodule remission. Eur J Obstet Gynecol Reprod Biol 2017;211:108-111 10.1016/j.ejogrb.2017.02.015

13 Jang HI, Kim SE, Kim TJ, et al. Catamenial hemoptysis accompanied by subcutaneous endometriosis treated with combination therapy. Obstet Gynecol Sci 2017;60(02):236-239 10.5468/ ogs.2017.60.2.236

14 Choi SY, Kim CK, Park CB. Successful treatment of catamenial hemoptysis by video-assisted thoracoscopic surgery. Thorac Cardiovasc Surg 2013;61(01):94-96 10.1055/s-0032-1330227

15 McCormack PL. Dienogest: a review of its use in the treatment of endometriosis. Drugs 2010;70(16):2073-2088 10.2165/11206320000000000-00000 